\title{
Predictors of eclampsia among preeclamptic patients: a case control study in Yaounde, Cameroon
}

\author{
Jeanne Hortence Fouedjio ${ }^{1,2}$, Pascal Foumane ${ }^{2}$, Jovanny Tsuala Fouogue ${ }^{4 *}$, Veronique Jordane \\ Mboua Ndenga ${ }^{2}$, Florent Ymele Fouelifack ${ }^{1,3,5}$, Agnès Esiene à Bissene ${ }^{1,6}$, \\ Philip Njotang Nana ${ }^{1,2}$, Loïc Dongmo Fouelifa ${ }^{7}$, Robinson Enow Mbu ${ }^{1,2}$, \\ Emile Télesphore Mboudou ${ }^{2,5}$
}

\author{
${ }^{1}$ Unit of Obstetrics and Gynaecology of the Yaounde Central Hospital, Cameroon \\ ${ }^{2}$ Department of Obstetrics and Gynaecology, Faculty of Medicine and Biomedical Sciences, University of Yaoundé 1, \\ Yaoundé, BO Box: 1364 Cameroon \\ ${ }^{3}$ Research, Education and Health Development Group, Gares falaise, Dschang, Cameroon \\ ${ }^{4}$ Douala Gynaeco Obstetric and Pediatric Hospital, PO Box: 7270 Douala-Cameroon \\ ${ }^{5}$ Department of Obstetrics and Gynecology, Higher Institute of Medical Technology of Nkolondom, Yaoundé, \\ Cameroon \\ ${ }^{6}$ Department of surgery and specialties, Faculty of Medicine and Biomedical Sciences, University of Yaoundé 1, \\ Yaoundé, BO Box: 1364 Cameroon \\ ${ }^{7}$ Faculty of Medicine, University of Lomé, Togo, School of Armies Health Services of Lomé, Togo
}

Received: 28 April 2016

Accepted: 02 June 2016

\section{*Correspondence: \\ Dr. Jovanny Tsuala Fouogue, \\ E-mail: fotsujo@outlook.com}

Copyright: (c) the author(s), publisher and licensee Medip Academy. This is an open-access article distributed under the terms of the Creative Commons Attribution Non-Commercial License, which permits unrestricted non-commercial use, distribution, and reproduction in any medium, provided the original work is properly cited.

\section{ABSTRACT}

Background: Preeclampsia is a major cause of maternal mortality. Eclampsia is a dramatic complication of preeclampsia. This study aimed at identifying clinical predictors of eclampsia among preeclamptic patients.

Methods: We carried out a case-control study from November 1, 2014 to April 30, 2015 in six health facilities in Yaounde. Cases were women who have had eclamptic seizures antepartum, perpartum or within 48 hours of delivery. Controls were preeclamptic women who did not convulse till 48 hours after delivery. Unadjusted and adjusted Odds Ratios were calculated.

Results: After univariable analysis the following parameters were associated with eclampsia: headache (uOR: 2.9; 95\% CI: 1.4-6.2) and absence of stable income (uOR: 17.6; 95\% CI: 6.2-49.8). After multivariate analysis predictors of eclampsia among pre-eclamptic patients were: age <20 years (aOR: 2.5; 95\% CI: 1.0-5.9), family history of high blood pressure in the mother (aOR: 4.8; 95\% CI: 1.2-19.3), antenatal care by a nurse auxiliary (aOR: 9.3; 95\% CI: 2.4-35.9), right upper abdominal quadrant pain (aOR: 9.9; 95\% CI:1.2-77.9) visual disturbances (aOR:7.9; 95\% CI: 2.3-26.9).

Conclusions: These predictors of eclampsia can be used for early initiation of aggressive preventive therapy in preeclamptic patients.

Keywords: Pre-eclampsia, Eclampsia, Predictors, Hypertension, Pregnancy, Cameroon

\section{INTRODUCTION}

Ninety nine percent of the 800 daily maternal deaths occurring worldwide are recorded in developing countries. ${ }^{1}$ Hypertensive disorders in pregnancy are the third cause of maternal mortality. ${ }^{1,2}$ Pre-eclampsia complicates $0.5-2 \%$ of pregnancies in rich countries. In Cameroon, the prevalence of hypertensive disorders in pregnancy is $8.2 \%$ while that of pre-eclampsia is between 5.9 and $6.4 \% .^{3-5}$ In 2009 , eclampsia occurred in 9.5 out of 
1000 deliveries at the Yaounde General Hospital. ${ }^{6}$ Hypertensive disorders were the third cause of maternal mortality at the Yaounde central Hospital and the second cause at the Yaounde General Hospital. ${ }^{8}$ These hospitals are the most important health facilities in the country's capital. A study carried out in the referral Hospital of the most populated region of Cameroon revealed that eclampsia was the cause of $17.5 \%$ of maternal deaths. Given that national statistics are not available those figures can be extrapolated to the whole country. An unpublished study conducted at the Yaounde gynaecoobstetric and pediatric hospital in 2010 revealed that eclamptic seizures occur in $2-3 \%$ of pre-eclamptic women without appropriate prophylaxis. ${ }^{8}$ The aim of this study was to determine clinical predictors of eclampsia among pre-eclamptic women.

\section{METHODS}

This case-control study was carried out in six health facilities in Yaounde: two tertiary hospitals (the Yaounde gynaeco-obstetric and pediatric hospital (YGOPH), the Yaounde central hospital (YCH)), three district hospitals. (The Efoulan district hospital (EDH), the Cite-Verte district hospital (CDH) and the Biyem-Assi district hospital (BDH)) and one faith-based hospital (centre d'animation sociale et sanitaire of Nkoldongo (CASS)). The study was conducted from November 1, 2014 to April 30, 2015.

Cases were women who had eclamptic seizures during pregnancy, labour or within 48 hours of delivery. Controls were preeclamptic women who did not have seizures untill the 48th hour post-partum. Schlesselman's formula was used to determine the minimal sample size (at least 25 subjects per group). Sampling was consecutive and non-probabilist. CS Pro ${ }^{\circledR}$ version 5.0 and SPSS $®$ version 20.0 softwares were used respectively for data collection and for statistical analysis.

Exposures variables were socio-demographical (age, marital status, occupation, level of instruction, stability of income) and clinical (gestity, parity, pre-gestational body mass Index, headache, tinnitus aurium, nausea/vomiting, epigastric pain, right upper quadrant pain, visual disturbances, pedal œdema, vertigo/drowsiness, dyspnoea, tendon reflexes, systolic blood pressure, diastolic blood pressure and diuresis).

The probability on type 1 error was 0.05 . Unadjusted and adjusted Odds Ratios (OR) with $95 \%$ confidence intervals $(\mathrm{CI})$ were used to measure association between exposure variables and eclampsia. Only variables found to be associated with eclampsia after univariate analysis were included in the model of multiple logistic regressions. Chi2 test and Fisher's exact test were used to compare qualitative variables. A clearance was obtained from the institutional ethical committee of the Yaoundé gynaeco-obstetric and pediatric hospital $\left(\mathrm{N}^{\circ} \mathrm{CE}\right.$ E933/ CE/ MINSANTE /HGOPY/ PCA/DG/DGA/SCAJ/nm. Administrative clearances were obtained from the management of each hospital where we recruited participants. Data were collected after informed consent and were managed confidentially and anonymously. Participants were recruited within 48 hours of delivery. All patients presenting severe pre-eclampsia were treated by magnesium sulphate and nicardipine.

\section{RESULTS}

Out of the 228 women admitted for preeclampsia during the study period, 226 were included (two patients refused to participate). Sixty three of the $226(27.9 \%)$ participants had eclampsia.

\section{Associations between participants' characteristics and eclampsia}

Table 1 shows associations of participants' characteristics with eclampsia (univariate analysis). Age younger than 20 years old was strongly associated with eclampsia (uOR: 3.4; 95\% CI: 1.6-7.2). University education was protective against eclampsia (uOR: 0.3 ; 95\% CI: 0.1-0.7). Absence of a stable income was strongly associated with eclampsia (uOR: 17.6; 95\% CI: 6.2-49.8). Primiparity was associated with eclampsia (uOR: 2.7 ; 95\% CI: $1.4-$ 5.3). Antenatal care by a nursing auxillary was associated with eclampsia (uOR: 5.0; 95\% CI: 2.2-11.7) while care by an obstetrician-gynaecologist was protective (uOR:0.3; 95\% CI: 0.1-0.8).

\section{Associations between symptoms and eclampsia}

Table 2 shows distribution of symptoms and their associations with eclampsia (univariate analysis). The following symptoms were associated with the occurrence of eclampsia: headache (uOR: 2.9; 95\% CI: 1.4-6.2), visual disturbances (uOR: 4.4; 95\% CI: 2.3-8.8), epigastric pain (uOR: 2.5 ; 95\% CI: $1.4-4.7$ ) and right upper abdominal quadrant pain (uOR: 8.6; 95\% CI: 2.727.7).

\section{Associations between physical signs and eclampsia}

Table 3 shows associations between physical signs and eclampsia (univariate analysis). The following signs were associated with eclampsia: exaggerated tendon reflexes (uOR: 4.3; 95\% CI: 1.9-9.8), diastolic blood pressure above 110 millimetres of mercury $\mathrm{mmHg}$ (uOR: 2.2; 95\%CI: 1.2-3.9), pre-gestational body mass index (BMI) less than 25 kilograms/square metre $\left(\mathrm{kg} / \mathrm{m}^{2}\right)$ : (uOR: 2.5;95\% CI: 1.4-4.6). Oedema of the lower limbs was not associated with eclampsia (uOR: 1.1;95\% CI: 0.5-2.3). 
Table 1: Associations of participant's characteristics with eclampsia.

\begin{tabular}{|c|c|c|c|}
\hline Characteristics & Eclampsia $N=63$ & No eclampsia $N=63$ & uOR $(95 \%$ CI $)$ \\
\hline Age (years) & $\mathbf{N}(\%)$ & $\mathbf{N}(\%)$ & \\
\hline$<20$ & $18(28.6)$ & $17(10.4)$ & $3.4(1.6-7.2)$ \\
\hline $20-25$ & $22(34.9)$ & $40(24.5)$ & $2.1(1.1-4.0)$ \\
\hline $26-30$ & $10(15.9)$ & $58(35.6)$ & $0.4(0.2-0.9)$ \\
\hline$\geq 31$ & $13(20.6)$ & $48(29.5)$ & $0.5(0.3-1.02)$ \\
\hline \multicolumn{4}{|l|}{ Level of education } \\
\hline None & $2(3.2)$ & $5(3.1)$ & $1.0(0.2-5.5)$ \\
\hline Primary & $12(19.0)$ & $16(9.8)$ & $2.2(0.9-4.9)$ \\
\hline Secondary & $41(65.1)$ & $87(53.4)$ & $1.6(0.9-2.8)$ \\
\hline Tertiary & $8(12.7)$ & $55(33.7)$ & $0.3(0.1-0.7)$ \\
\hline \multicolumn{4}{|l|}{ Stability of income } \\
\hline Yes & $4(6.3)$ & $43(26.4)$ & $0.2(0.1-0.6)$ \\
\hline No & $59(93.7)$ & $120(73.6)$ & $17.6(6.2-49.8)$ \\
\hline \multicolumn{4}{|l|}{ Parity } \\
\hline 1 & $32(50.8)$ & $61(37.4)$ & $2.7(1.4-5.3)$ \\
\hline $2-3$ & $26(41.3)$ & $75(46)$ & $2.3(1.1-5.1)$ \\
\hline $4-5$ & $4(6.3)$ & $19(11.7)$ & $1.1(0.3-3.8)$ \\
\hline$\geq 6$ & $1(1.6)$ & $8(4.9)$ & $0.6(0.7-5.2)$ \\
\hline \multicolumn{4}{|l|}{ Family history of HTN in mother } \\
\hline Oui & $36(57,1)$ & $48(29,4)$ & $3.2(1.8-5.8)$ \\
\hline Non & $27(42,9)$ & $115(70,6))$ & $0.3(0.2-0.6)$ \\
\hline Qualification of health staff at ANC & $\mathrm{N}=59(100)$ & $\mathrm{N}=160(100)$ & \\
\hline Nursing auxillary & $16(27.1)$ & $11(6.9)$ & $5.0(2.2-11.7)$ \\
\hline Nurse/midwife & $36(61.0)$ & $90(56.3)$ & $1.2(0.7-2.2)$ \\
\hline GP & $0(0.0)$ & $12(7.5)$ & NA \\
\hline Obstetrics/gynaecology & $7(11.9)$ & $47(29.4)$ & $0.3(0.1-0.8)$ \\
\hline
\end{tabular}

Table 2: Associations between symptoms and eclampsia.

\begin{tabular}{|c|c|c|c|}
\hline Symptoms & Eclampsia $N=63$ & No eclampsia $\mathbf{N}=163$ & uOR $(95 \%$ CI $)$ \\
\hline \multicolumn{4}{|c|}{ Tinnitus aurium } \\
\hline Yes & $8(12.7)$ & $16(9.8)$ & $1.1(0.4-2.7)$ \\
\hline No & $55(87.3)$ & $147(90.2)$ & $0.8(0,3-1,9)$ \\
\hline \multicolumn{4}{|l|}{ Headache } \\
\hline Yes & $51(82.3)$ & $81(61.2)$ & $2.9(1.4-6.2)$ \\
\hline No & $12(17.7)$ & $52(38.8)$ & $0.4(0.2-0.8)$ \\
\hline \multicolumn{4}{|c|}{ Visual disturbances } \\
\hline Yes & $41(66.1)$ & $41(30.6)$ & $4.4(2.3-8.8)$ \\
\hline No & $22(33.9)$ & $122(69.4)$ & $0.2(0.1-0.3)$ \\
\hline \multicolumn{4}{|c|}{ Epigastric pain } \\
\hline Yes & $31(50)$ & $38(28.4)$ & $2.5(1.4-4.7)$ \\
\hline No & $32(50)$ & $125(71.6)$ & $0.3(0.2-0.6)$ \\
\hline \multicolumn{4}{|c|}{ Right upper quadrant pain } \\
\hline Oui & $13(21)$ & $4(3)$ & $8.6(2.7-27.7)$ \\
\hline Non & $50(79)$ & $159(97)$ & $0.1(0.03-0.3)$ \\
\hline
\end{tabular}

uOR: unadjusted odds ratio; CI: confidence interval. 
Table 3: Associations between physical signs and eclampsia.

\begin{tabular}{|llll|}
\hline Physical signs & Eclampsia $\mathbf{N}=\mathbf{6 3}$ & No eclampsia $\mathbf{N}=\mathbf{1 6 3}$ & uOR (95\% CI) \\
\hline Exaggerated tendon reflexes & & & \\
\hline Yes & $38(60.3)$ & $49(28.2)$ & $4.3(1.9-9.8)$ \\
\hline No & $10(15.9)$ & $56(34.4)$ & $0.4(0.2-0.8)$ \\
\hline Not tested & $15(23.8)$ & $58(37.4)$ & $0.6(0.3-1.1)$ \\
\hline Systolic blood pressure & & & $0.6(1.3-1.1)$ \\
\hline$<160$ & $25(39.7)$ & $84(51.5)$ & $1.6(0.9-2.9)$ \\
\hline$\geq 160$ & $38(60.3)$ & $79(48.5)$ & $0.5(0.3-0.8)$ \\
\hline Diastolic blood pressure & & & $2.2(1.2-3.9)$ \\
\hline$<110$ & $36(57.1)$ & $42(25.7)$ & $1.1(0.5-2.3)$ \\
\hline$\geq 110$ & $27(42.9)$ & & $0.9(0.5-1.9)$ \\
\hline Edema of the lower limbs & & $130(79.8)$ & \\
\hline Yes & $51(81)$ & $33(20.2)$ & $2.5(1.4-4.6)$ \\
\hline No & $12(19)$ & $61(37.4)$ & $0.7(0.4-1.6)$ \\
\hline Pre-gestational BMI $\left(\mathbf{k g} / \mathbf{m}^{2}\right)$ & & $67(41.1)$ & $0.3(0.1-0.7)$ \\
\hline$<25$ & $38(60.4)$ & $37(21.5)$ & \\
\hline $25-30$ & $21(33.3)$ & & \\
\hline$\geq 30$ & $4(3.3)$ & & \\
\hline
\end{tabular}

BMI: body mass index; $\mathrm{Kg}$ : klogramme; $\mathrm{m}^{2}$ : square metre

\section{Predictors of eclampsia among pre-eclamptic patients}

Table 4 shows predictors of eclampsia after multiple logistic regression. After adjustments only the following independent variables were still associated with eclampsia: right abdominal upper quadrant (aOR: 9.9; 95\% CI: $1.2-77.9)$, antenatal care by a nursing auxillary (aOR: 9.3; 95\% CI: 2.4-35.9), visual disturbances (aOR: 7.9; 95\% CI: 2.3-26.9), family history of high blood pressure in mother (aOR:4.8; 95\% CI: 1.2-19.3), age younger than 20 years (aOR: 2.5; 95\% CI: 1.0-5.9).

Table 4: Predictors of eclampsia after multivariable analysis.

\begin{tabular}{|lll|}
\hline Predictors & aOR & $95 \%$ CI \\
\hline Right upper quadrant pain & 9.9 & $1.2-77.9$ \\
\hline ANC by nursing auxiliary & 9.3 & $2.4-35.9$ \\
\hline Visual disturbances & 7.9 & $2.3-26.9$ \\
\hline Family history of HTN in mother & 4.8 & $1.2-19.3$ \\
\hline Age < 20 years & 2.5 & $1.0-5.9$ \\
\hline
\end{tabular}

ANC : antenatal consultation. HTN: hypertension. aOR: adjusted odds ratio

\section{DISCUSSION}

In our series the prevalence of eclampsia among preeclamptic was $27.9 \%(63 / 226)$. This result is similar to that reported by Moj et al. in Madagascar in 2011 $(31.8 \%)$, but lesser than that obtained by Tebeu et al. in far north Cameroon in $2012(36.8 \%))^{9,10} \mathrm{We}$ found that age under 20 years was an independent risk factor of eclampsia among pre-eclamptic patients with an odds ratio of 2.5 (95\% CI: 1.0-5.9). In far north Cameroon (2012), Tebeu et al. found that maternal age under 20 years was strongly associated with eclampsia (OR: 8.5; 95\% CI: 4.0-18.6) among women presenting hypertensive disorders in pregnancy. ${ }^{10}$

In the United States of America (USA), Coghill et al. had similar findings in 2011. ${ }^{11}$ Mayi-Tsonga et al. also found age under 19 to be associated with eclampsia in Gabon in 2006 (OR: 3.4 ; 95\% CI: $1.8-6.5$ ). ${ }^{12}$ On the contrary, in a review of controlled studies, Duckitt et al. concluded that young maternal age did not seem to affect the risk of developing pre-eclampsia, whichever cut off age was used. ${ }^{13}$ This may be due to the fact that the studies they reviewed were carried out in populations different from ours. Clinicians in our context should therefore be more vigilant vis-à-vis seizures in teenagers with preeclampsia.

In our study, antenatal care (ANC) by a nursing auxillary was associated with eclampsia (aOR: 9.3; 95\% CI: $2.4-$ 35.9). This is a very important fact in Cameroon where $62.3 \%$ of antenatal consultations are carried out by nurses, midwifes and nursing auxiliaries. ${ }^{14}$ Further training in better management (immediate referral to obstetrician-gynecologist) of women diagnosed with preeclampsia should be organized for those nursing auxiliaries providing antenatal care. Indeed, antenatal care by obstetrician-gynecologist was protective against eclampsia among pre-eclamptic women (uOR: 0.3; $95 \%$ CI: 0.1-0.8).

Family history of hypertension in the mother was associated with eclampsia (aOR: 4.8; 95\% CI: 1.2 -19.3) in our study. In a study far north Cameroon Tebeu et al. found that family history of hypertension in a first degree 
relative was not associated with eclampsia among women with pregnancy-related hypertension. ${ }^{10}$

In our series, primiparity (uOR: $2.795 \%$ CI: 1.4-5.3), primigravidity (uOR: 3.1; 95\% CI: 1.7-5.6), and pauciparity (uOR: $2.34 ; 95 \%$ CI: (1.1-6.1) increased the risk of eclampsia. Duckitt et al. reported that nulliparity tripled the risk of pre-eclampsia (uOR: 2.91. 95\% CI: 1.36.6) and Tebeu et al. found that nulliparity multiplied by nine the risk of eclampsia among women with pregnancy related hypertension (uOR: 9.2;95\% CI: 3.1-27.7). ${ }^{10,13}$ Kullberg et al. reported similar findings with a two-fold increased risk of eclampsia among nulliparous. ${ }^{15}$ These findings support the immunologic theory of preeclampsia stating the primo movens of pre-eclampsia is rejection of sperm cells by the mother's immune system after a short period of sexual cohabitation. ${ }^{16}$

Right upper abdominal quadrant pain (aOR: 9.9; 95\% CI: 1.2-77.9), headache (uOR: 2.9; 95\%CI: 1.4-6.2) and (aOR: 7.9; 95\% CI: 2.3-26.9) visual disturbances were associated with eclampsia in our series. Salem B et al. reported similar findings. ${ }^{17}$ Indeed those signs are classically referred to as signs of imminent eclampsia. ${ }^{18}$

\section{CONCLUSION}

Eclampsia is a common complication of pre-eclampsia. This study has identified some predictors that can be used to initiate aggressive preventive therapy among preeclamptic patients at higher risk of developing eclampsia.

\section{ACKNOWLEDGEMENTS}

Authors express their gratitude to the staff of the following hospitals: the Yaounde gynaeco-obstetric and pediatric hospital, the Yaounde central hospital, the Efoulan district hospital, the Cite-Verte district hospital, the Biyem-Assi district hospital and the centre d'Animation sociale et Sanitaire of Nkoldongo for the permission to conduct the research in their facilities. They also thank all participants for their contribution.

\section{Funding: No funding sources}

Conflict of interest: None declared

Ethical approval: The study was approved by the Institutional Ethics Committee of the Yaounde GynaecoObstetric and Pediatric Hospital

\section{REFERENCES}

1. Sprunck A, Collange O, Pottecher T. Prééclampsie, éclampsie, HELLP syndrome : définitions, éléments de diagnostic et de prise en charge. 51 e Congrès national d'anesthésie et de réanimation. Médecins. Urgences vitals. 2009:1-9.

2. OMS Mortalité maternelle. WHO 2014. Available at http://www.who.int/mediacentre/factsheets/fs348/fr/. Accessed 26 March 2015.
3. Mboudou E, Foumane P, Belley Priso E, Dohbit J, Ze Minkande J, Nkengafac WM. l'Hypertension au cours de La Grossesse: Aspects cliniques et épidémiologiques à l'Hôpital Gynéco-Obstétrique et Pédiatrique de Yaoundé, Cameroun. Clin Mother Child Health. 2009;6(2):1087-93.

4. Leke RJI. Outcome of delivery at the central maternity. Ann Univ Sc Santé. 1987;4(1):332-0.

5. Kyebyene MA. Evaluation de la prise en charge des complications de la pré-éclampsie à l'Hôpital Central de Yaoundé mémoire de diplôme de spécialiste en sciences cliniques. Yaoundé Cameroun. Faculté de Médecine et des Sciences Biomédicales. Université de Yaoundé I; 2013.

6. Belley Priso E, Njamen TN, Coulibaly A, Mboudou E, Doh A. L'éclampsie A L'Hôpital General De Douala: Aspects Épidémiologiques Et Pronostiques. Health Sci Dis. 2013;10(4).

7. Tebeu PM, Ngassa P, Kouam L, Major AL, Fomulu JN. Maternal mortality in maroua provincial hospital, Cameroon (2003-2005). West Indian Med J. 2007;56(6):502-7.

8. Abdoulaye N. Mortalité maternelle à l'Hôpital Général de Yaoundé: Etude rétrospective 1996-2005. Yaoundé: Faculté de Médecine et des Sciences Biomédicales. Université de Yaoundé I; 2006.

9. Moj HN, Randriambololona DMA, Rasolonjatovo T, Ranoaritiana DB, Fidison A, Rakotoambinina B. De la pré-éclampsie à l'éclampsie: quels sont les facteurs de risque? Rev Trop Chir. 2010;4:30-2.

10. Tebeu PM, Halle G, Lemogoum D, Simo WAG, Kengne FG, Fomulu JN. Risk factors for eclampsia among patients with pregnancy-related hypertension at Maroua Regional Hospital, Cameroon. Int J Gynaecol Obstet. 2012;118(3):254-6.

11. Coghill AE, Hansen S, Littman AJ. Risk factors for eclampsia: a population-based study in Washington State, 1987-2007. Am J Obstet Gynecol. 2011;205(6):553e1-553e7.

12. Mayi-Tsonga S, Akouo L, Ngou-Mve-Ngou JP, Meye JF. Facteurs de risque de l'éclampsie à Libreville (Gabon): étude cas-témoins. Cah D'études Rech Francoph. 2006;16(3):197-200.

13. Duckitt K, Harrington D. Risk factors for preeclampsia at antenatal booking: systematic review of controlled studies. BMJ. 2005;330(7491):565.

14. National institute of statistics-Cameroon. Demographic, health and multiple indicators cluster survey 2011. Yaounde: institut national de statistique; 2012. Available at http://www.statisticscameroon.org/manager.php?id=6.

15. Kullberg G, Lindeberg S, Hanson U. Eclampsia in Sweden. Hypertens Pregnancy. 2002;21(1):13-21.

16. Robillard P, Hulsey T, Pénanin J, Janky E, Miri E, Papiernik E. Association of pregnancy-induced hypertension with duration of sexual cohabitation before conception. Lancet. 1994;344:973-5.

17. Ben Salem F, Ben Salem K, Grati L, Arfaoui C, Faleh R, Jamel A, et al. Facteurs de risque 
d'éclampsie: étude cas-témoins. Ann Fr Anesth Réanimation. 2003;22(10):865-9.

18. Hypertensive Disorders in Pregnancy. In: Cunningham FG, Levenno KJ, Bloom SL, Hauth JC,
Gilstrap III LC, Wenstrom KD, eds. Williams Obstetrics. 22nd edition. New York. McGraw-Hill Companies; 2005:34.

Cite this article as: Fouedjio $\mathrm{JH}$, Foumane $\mathrm{P}$, Fouogue JT, Ndenga VJM, Fouelifack FY, Bissene AE, et al. Predictors of eclampsia among preeclamptic patients: a case control study in Yaounde, Cameroon. Int J Reprod Contracept Obstet Gynecol 2016;5:2204-9. 